\title{
PERCUTANEOUS EMBOLISATION OF MAJOR SPINAL CORD ARTERY AS A TREATMENT FOR INTRACTABLE SPASTICITY
}

\author{
By Keirchi Shibasaki, M.D., Sadaaki Nakai, M.D. and Masataka Higuchi, M.D. \\ Department of Orthopaedic Surgery, National Murayama Hospital. \\ 2-37-I Gakuen-Musashimurayama-Shi Tokyo Fapan.
}

\begin{abstract}
Percutaneous embolisation of Adamkiewicz's artery was undertaken to control the intractable spasticity of the lower extremities in ten cases of late stage spinal cord paralysis. Major effects were found in muscles innervated by obturator and femoral nerves and the voiding function of the automatic bladder was preserved in all cases. Discussion on the circulation dynamics of the lower spinal cord segments is presented in this paper.
\end{abstract}

Key words: Intractable lower limb spasticity; Percutaneous embolisation; Adamkiewicz's artery; Automatic bladder function.

\section{Introduction}

THE major spinal cord artery of the lower thoracic segments and the lumbar enlargement is known as Adamkiewicz's artery, or arteria radiculomedullaris magna, which is usually a single artery to vascularise the anterior two-thirds of those spinal cord segments. Based on angiographic findings of the injured spinal cord percutaneous embolisation of the major spinal cord artery was carried out to intercept the reflex arcs of the lower extremities. Satisfactory results were obtained in most of the cases.

\section{Materials and Method}

Percutaneous embolisation was undertaken in ten cases of late stage spinal cord paralysis. Seven were paraplegics and three were quadriplegic. All of them had complete transverse lesions. Problems for these patients include difficulty in transferring to and from the wheel-chair, in wearing clothes, in voiding urine and in maintaining a sitting position in bed (Table I).

Selective angiography of the spinal cord artery was carried out in order to find the major artery of the lower thoracic and the lumbar segments. A radioopaque polyethylene catheter (KIFA-red, Sweden) was used. After identifying Adamkiewicz's artery, 15 to 20 small pieces of Gelfoam were injected into the artery through the same catheter. It was necessary to confirm the engagement of the tip of the catheter in the orifice of the artery before the injection. Immediately after the embolisation significant changes were noticed in muscle tonicity of the lower extremities in most cases. No further treatment was needed after this procedure except for 24 hours bed rest but rehabilitation programmes were continued from the next day.

\section{Results}

Results of this series of study are shown in Table 2. Excellent results were obtained in Cases I and 2, in which adduction and flexion spasticity of paralysed legs were completely eliminated after embolisation. Results in five other cases were considered good, in that adduction spasticity of the hip joints had disappeared but flexion spasm remained unchanged. Another single case had transient improvement after the procedure and two cases showed no remarkable 


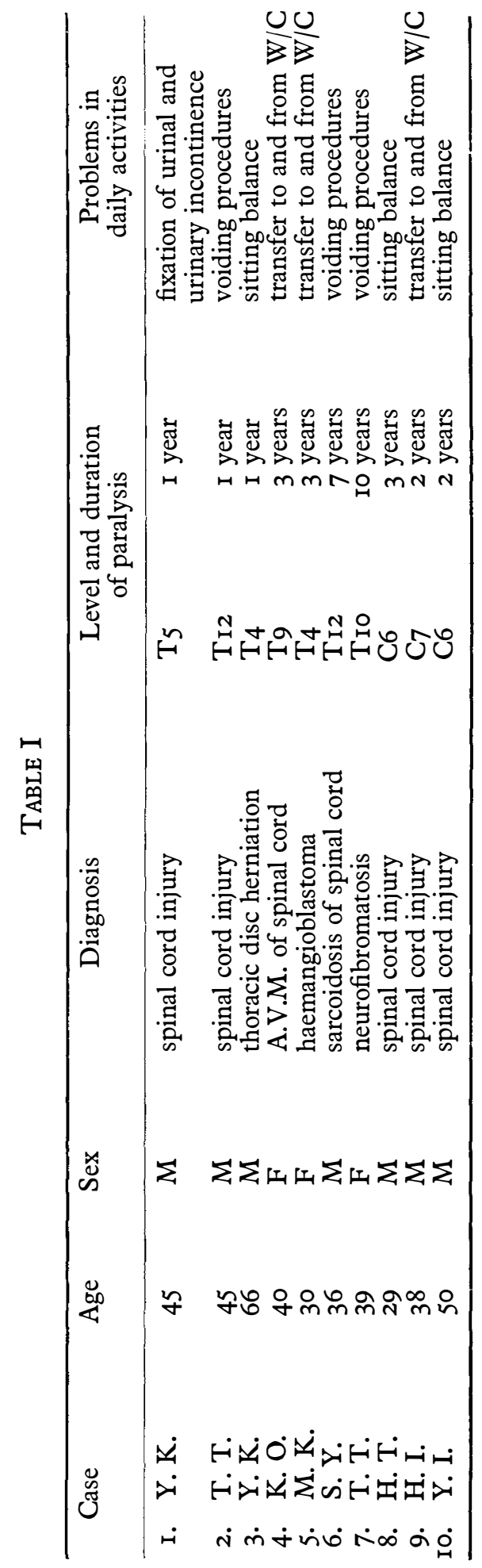


160

PARAPLEGIA

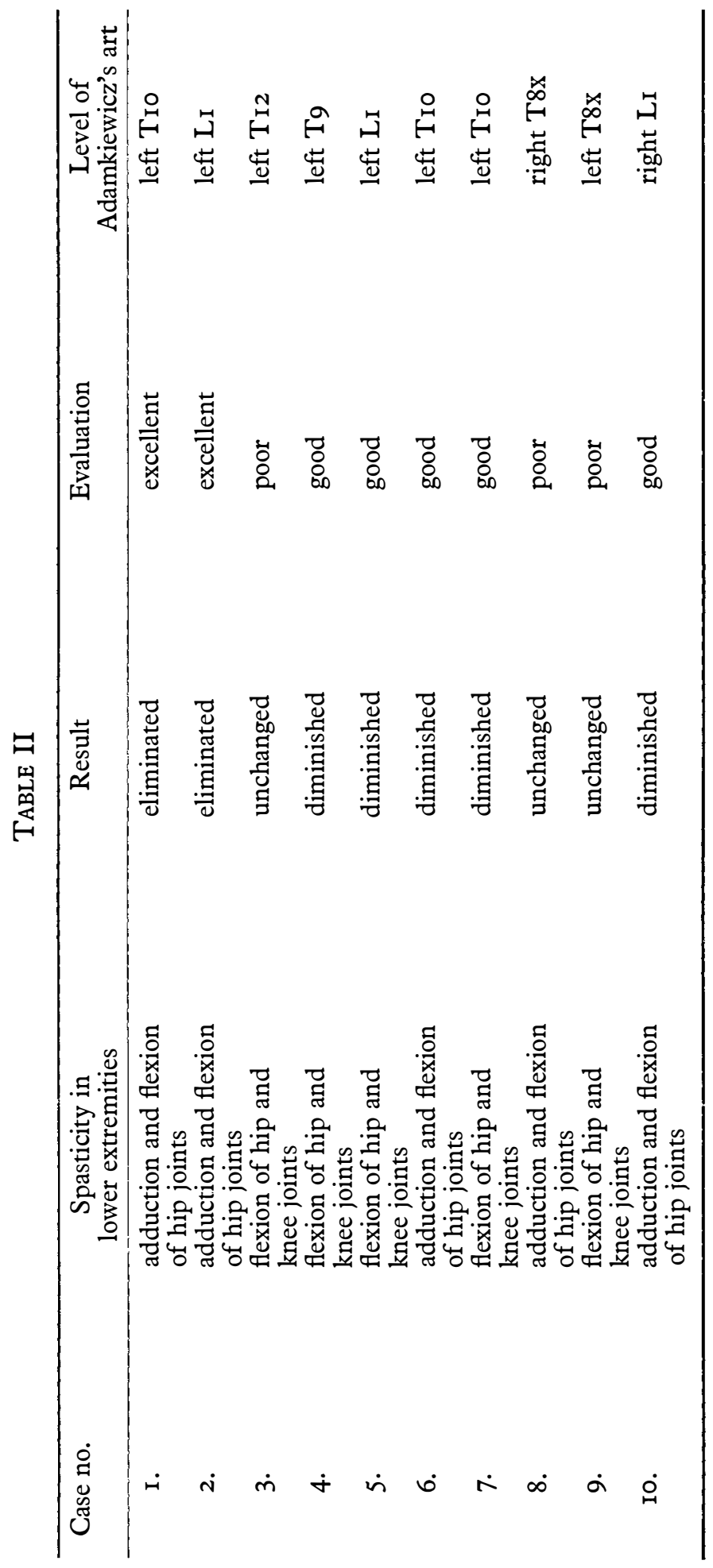


changes. In all cases the reflex function of the automatic bladder remained unchanged. The volume of post-voiding residuals was found decreased in some cases, as reduced adduction and flexion spasticity enabled the patients to void easily.

No serious complications were noticed after the procedure. Details of each case are as follows.

Case $\mathbf{r}$ had a I-year history of paraplegia after injury and showed excessive adduction and flexion spasticity of hip joints which made it difficult to fix a urinal to the perineal area. After embolisation marked reduction of spasticity enabled the patient to void easily and, in addition, the incidence of urinary incontinence became infrequent (Fig. I). However, cystometry showed no significant changes after the procedure.

Case 2 had similar problems to Case I and excessive spasticity was completely eliminated after the procedure. During the following 3 years there was no noticeable recurrence of the spasticity.

Case 3 showed complete paraplegia below $\mathrm{T}_{4}$ after surgery for disc herniation. Reduced flexion spasticity was noticed immediately after the embolisation procedure but the recurrence of spasticity was observed from the following day.

Case 4 had become paraplegic 3 years previously after resection of a vascular malformation of the spinal cord. Spinal cord angiography revealed that the feeding

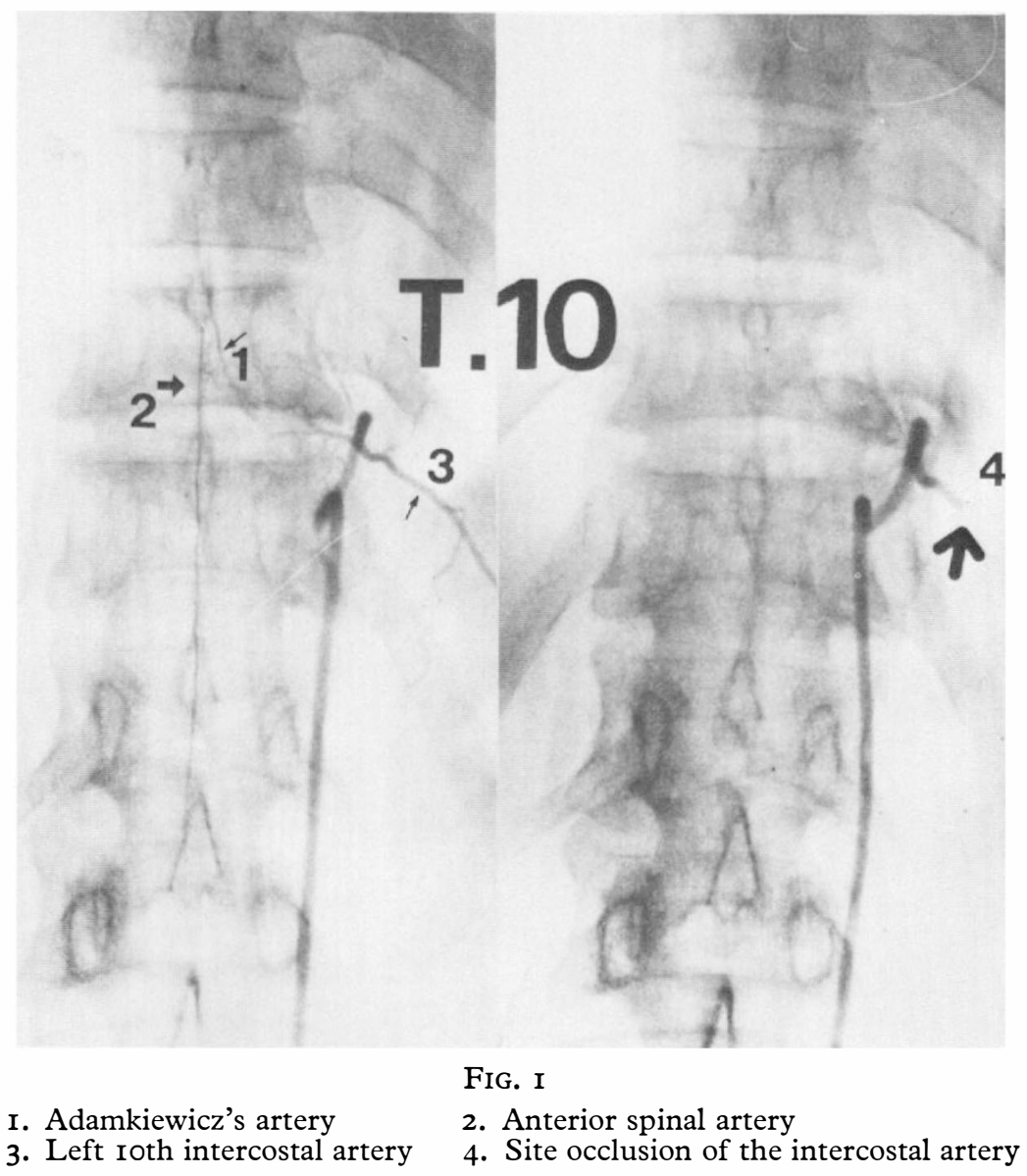


artery of the malformed vessel originated in Adamkiewicz's artery. Percutaneous embolisation was undertaken as a treatment for vascular malformation (Fig. 2). Neurological improvement was insignificant but the patient's mobility between bed and wheel chair became easier due to the reduced flexion spasticity of paralysed legs.

Case 5 had a 3-year history of paraplegia after an unsuccessful resection of haemangioblastoma of the spinal cord. One of the feeding arteries of the tumour was Adamkiewicz's artery. Embolisation of feeders was carried out to relieve ascending paraparesis. Neurological improvement in the upper extremities was obtained as well as reduced spasticity of the legs.

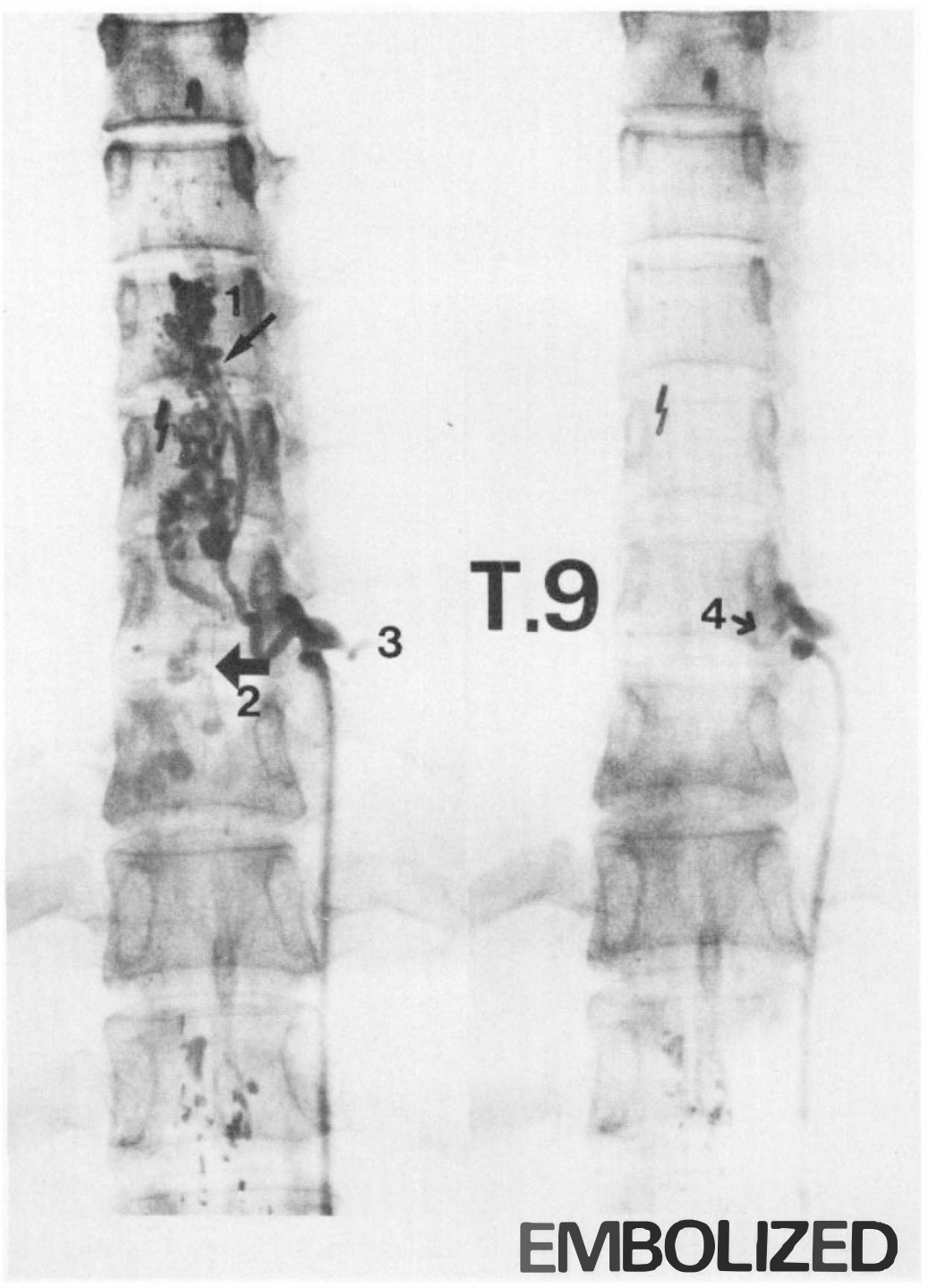

FIG. 2

I. Vascular malformation

3. Left 9th intercostal artery
2. Anterior spinal artery

4. Site occluded of feeding artery 


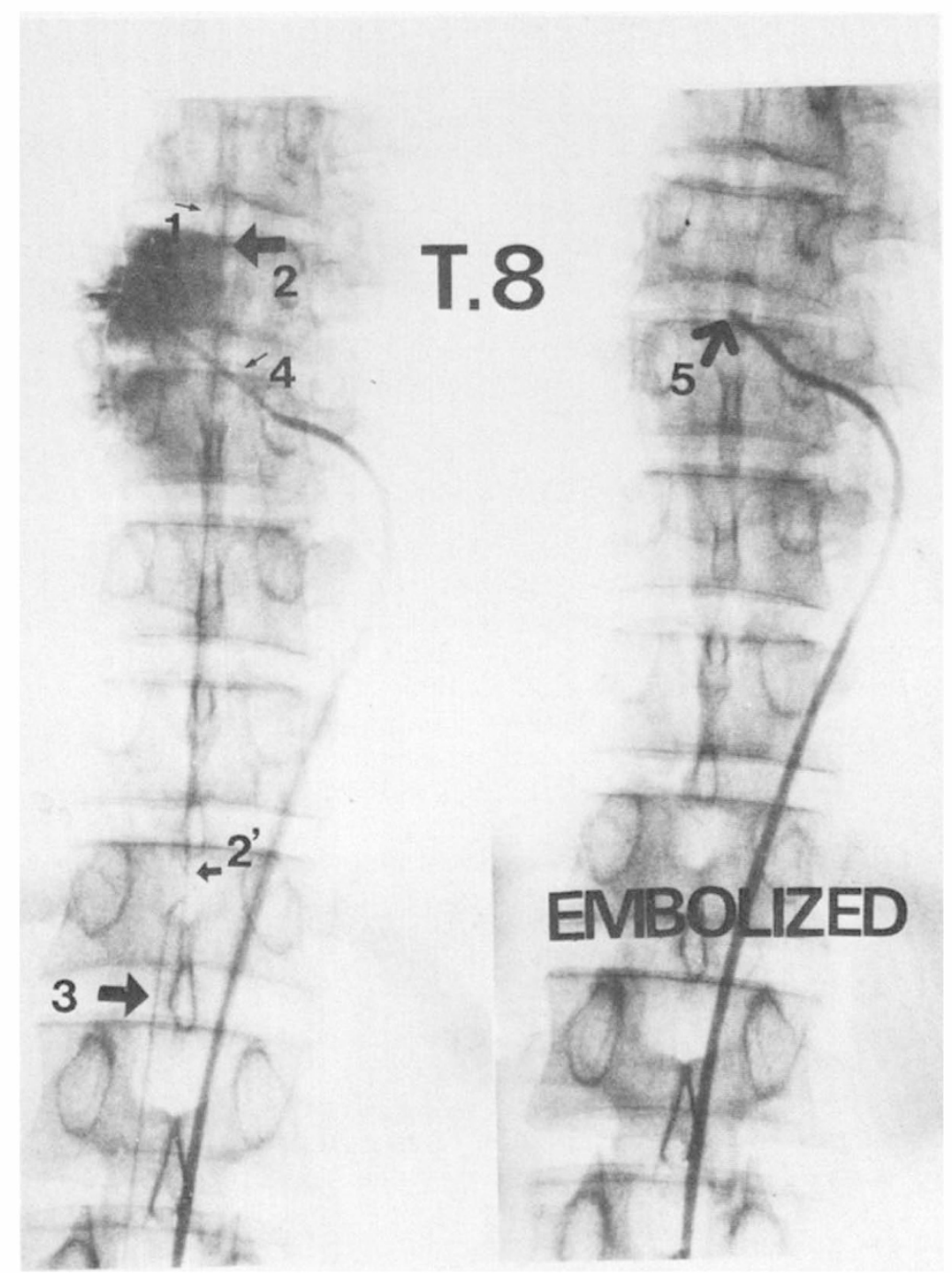

FIG. 3

I. Adamkiewicz's artery

3. Arteria conus medullaris
2. and 2'. Anterior spinal artery 4. Right 8 th intercostal artery 5. Site occluded of the intercostal artery

Case 6 was a case of spinal cord sarcoidosis showing complete paraplegia below TI2 for 7 years. Flexion and adduction spasticity of the hip joints disturbed voiding procedures. Reduction of adduction spasticity was noticed and the recanalisation of the occluded artery could not be observed angiographically 3 weeks later.

Case 7 was paraplegic due to neurofibromatosis and the embolisation procedure reduced the adduction spasticity. Voiding became easier. 
Case 8 had been quadriplegic since a traffic accident 3 years previously. Severe flexion spasticity of both legs was an obstacle in carrying out transferring procedures between bed and wheel chair. Angiographic findings suggested the existence of arteria conus medullaris in addition to Adamkiewicz's artery. However, the conus medullaris artery could not be embolised because of technical difficulty and no significant effect was observed after the embolisation of Adamkiewicz's artery (Fig. 3).

Case 9 was very similar to Case 8 and arteria conus medullaris was also observed and which was impossible to embolise. Change in spasticity was not observed after the embolisation of only Adamkiewicz's artery.

Case Io was also quadriplegic and had difficulty in maintaining a sitting position in a wheel chair due to flexion spasticity of both legs. This was minimised after embolisation.

\section{Discussion}

Excessive spasticity from the isolated cord is a serious obstacle to rehabilitation. Numerous therapeutic measures have been undertaken to control the intractable spasticity, which include drug therapies (Paeslack, 1965; Corbett, 1972; Guttmann, I973), chemical blocking (Gingras, I948; Avad, I972; Copp and Keenan, I972; Guttmann, I973), and several surgical techniques. However, the very multitude of treatments suggests that none of them is entirely satisfactory. Real effects and side-effects are still controversial in drug treatment and recurrence of the spasticity is a major problem in several peripheral surgical procedures, which include anterior and posterior rhizotomies (Foerster, I9II; Munro, I936), neurectomy (Selig, I9I4), myotomy (Michaelis, I964) and tenotomy (Michaelis, I964). Problems of myelotomy (Bishof, I952) and cordectomy (MacCarthy and Kiefer, I954), are the loss of re-established bladder function and other postoperative complications.

Before we tried embolisation we angiographically studied the blood supply of the injured spinal cord in 42 thoraco-lumbar patients and found a marked difference of angiographic findings between flaccid and spastic cases. The anterior spinal artery was not found below the injured level in flaccid cases (Fig. 4). In contrast, in spastic cases, the anterior spinal artery was found preserved, or supplementary anterior radicular arteries were recognised at the lumbar enlargement (Fig. 5).

Based on these findings, the percutaneous embolisation of Adamkiewicz's artery was undertaken to cause ischaemia of the lower spinal cord segments. The purpose of this procedure was to interrupt the reflex arcs of the lower extremities by decreasing the blood supply to the lumbar enlargement.

Significant changes in muscle tonicity were observed in the lower extremities in seven of ten cases after embolisation. Adduction and flexion spasms of hip joints were reduced or diminished in these cases but other spastic movements of the legs did not show any notable changes. In addition, bladder function was unchanged after the procedure. These results mean that the muscles innervated by the obturator and femoral nerves showed marked changes in their tonicity after the occlusion of Adamkiewicz's artery. The lower lumbar and sacral segments were not affected by the embolisation procedure. A possible explanation is that anastomosis between the anterior spinal artery and the two posterior spinal arteries might have provided sufficient collateral blood circulation at the conus level. 
PERCUTANEOUS EMBOLISATION OF MAJOR SPINAL CORD ARTERY I65

There was no correlation between the results and the level of origin of Adamkiewicz's artery. However, a supplementary artery should be considered to be present when the major artery is found above T8 level. This was pointed out and was called arteria conus medullaris by Lazorthes of France (I97I). In such a case Adamkiewicz's artery is not the only artery which supplies the lower thoracic segments and others below. Thus the embolisation of Adamkiewicz's

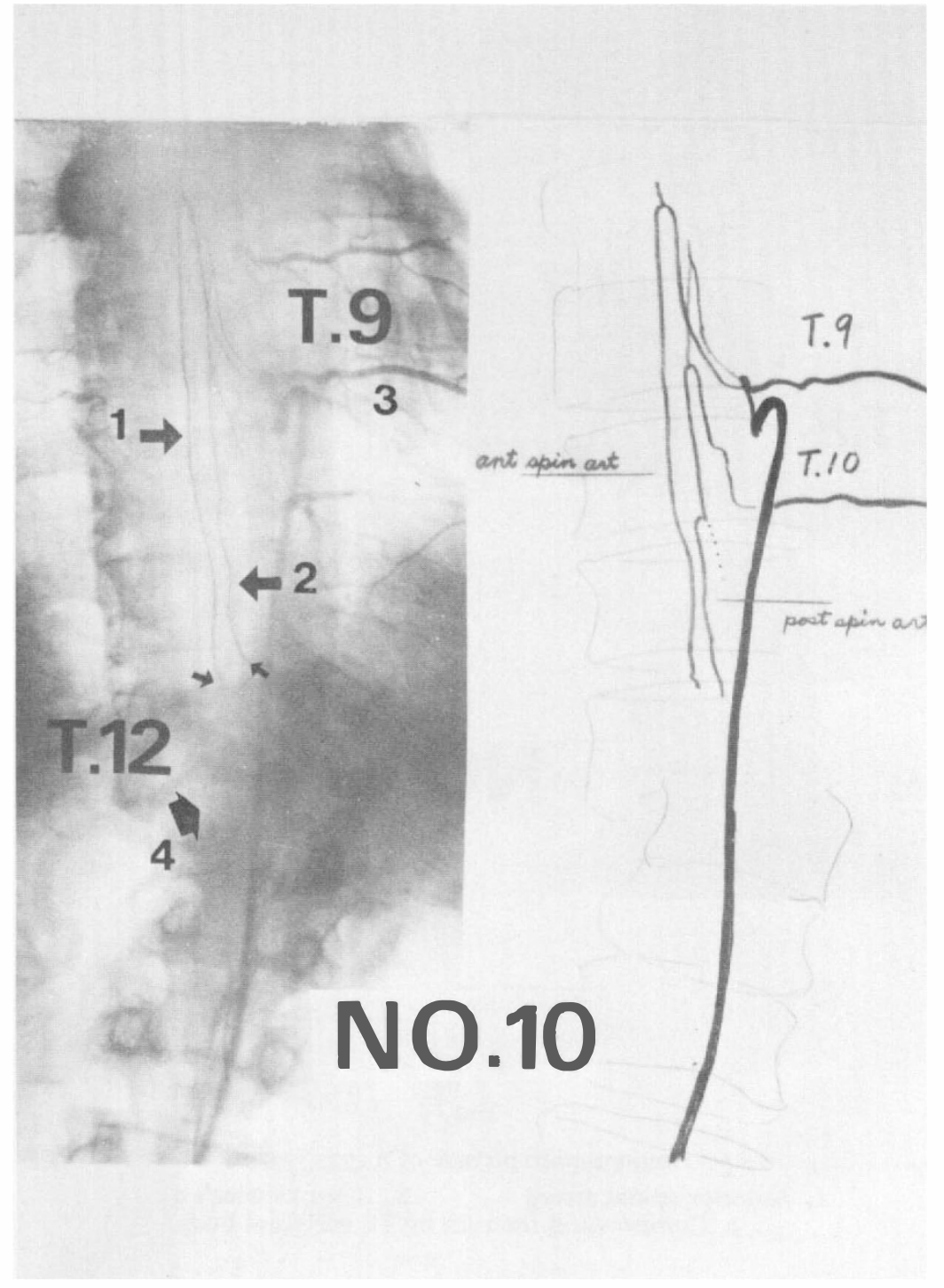

FIG. 4

Angiographic picture of a flaccid case

I. Anterior spinal artery

2. Left posterior spinal artery

3. Left 9th intercostal artery

4. Site of vertebral injury 


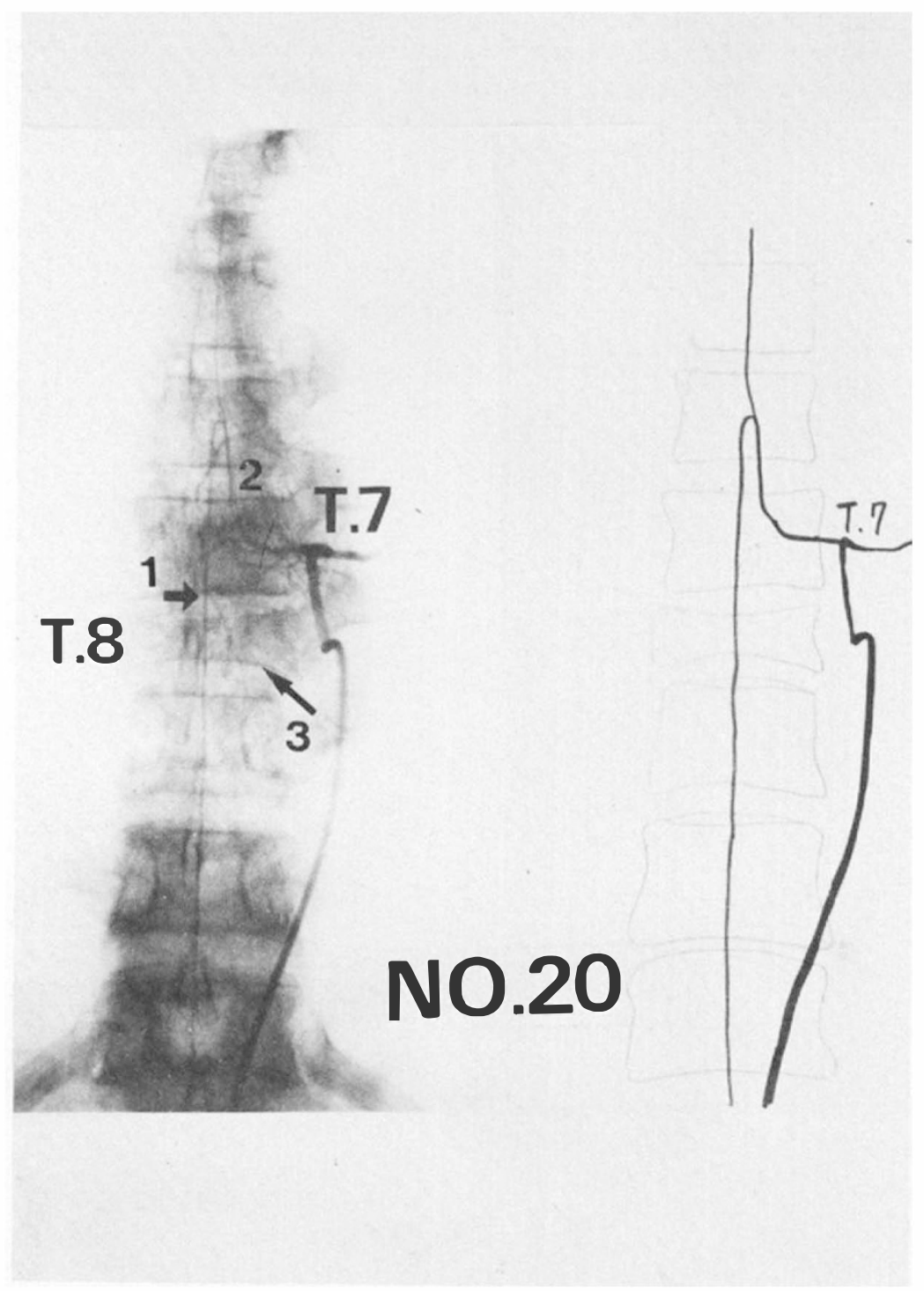

FIG. 5

Angiographic picture of a spastic case
I. Anterior spinal artery
2. Adamkiewicz's artery

3. Compression fracture of T8 vertebral body

artery above does not necessarily affect the lumbar enlargement of the spinal cord.

Compared with paraplegic cases, results in quadriplegic cases were not satisfactory. Levels adjacent to the original spinal cord lesion might be more vulnerable to ischaemic or other pathological conditions at more distant levels. However, further experience would be necessary to evaluate these results. 
In conclusion, the percutaneous embolisation of Adamkiewicz's artery reduced intractable spasticity of the lower extremities, thus eliminating the delay of the rehabilitation process in paraplegic and quadriplegic cases. It should be emphasised that automatic bladder function was always preserved during and after this procedure.

\section{SUMMARY}

Based on the angiographic findings of the injured spinal cord percutaneous embolisation of Adamkiewicz's artery was carried out to control intractable spasticity in ten cases of late stage spinal cord paralysis. The purpose of this procedure was to interrupt the reflex arcs of the lower extremities by decreasing the blood supply to the lumbar enlargement.

Results were excellent in two cases, good in five and poor in three. Major effects were found in adduction and flexion spasticity of the hip joints and bladder function was always preserved in these patients. It is speculated that occlusion of Adamkiewicz's artery mainly affected the lower thoracic and the upper lumbar segments. Anastomosis between the anterior spinal artery and the two posterior spinal arteries might have provided sufficient collateral blood circulation to the conus level.

It is emphasised that the percutaneous embolisation of Adamkiewicz's artery reduced the intractable spasticity of the lower extremities without changes in the voiding function of the automatic bladder.

\section{RÉSUMÉ}

Le Basant sur leurs observations angiographiques dans les lésions médullaires, les auteurs ont pratiqué l'embolisation percutanée de l'artère d'Adamkiewicz dans dix cas de myélopathie pour tenter d'en diminuer la spasticité gérante.

Le traitement a visé à d'interrompre les arcs réflexes des membres inferieurs en créant une ischémie médullaire au niveau du renflement lombaire. Les résultats ont été excellent dans deux cas, satisfaisnt dans cinq et mauvais dans trois.

Ce traitement s'est averé particulièrement efficace pour amélioler la spasticité en adduction et en flexion des hanches, alors que la fonction vésico-sphincterienne restant inchangée. Il semble que l'occlusion de l'artère d'Adamkiewicz affecte principalement les territoires des segments thoracique inférieurs et lombaires supérieurs.

Les anastomoses entre l'artère spinale antérieure et les deux artères spinales postérieures pourraient fournir l'irrigation vasculaire collatérale nécessaire au niveau du cône terminal. Ce travail met l'accent sur le fait que l'embolisation percutanée de l'artère d'Adamkiewicz améliore la spasticité rebelle des membres inférieurs sans aggraver les troubles vésicosphinctériens.

\section{ZUSAMMENFASSUNG}

Auf Grundlage der angiographischen Befunde des verletzten Rückenmarks wurde bei zehn Fällen lange bestehender Spinalparalyse eine perkutane Embolisierung der Adamkiewicz'schen Arterie durchgeführt, um die schwere Spastizität zu mindern. Zweck dieser Methode war es, die Reflexbögen der unteren Extremitäten durch Verminderung der Blutzufuhr zur lumbalen Vergrößerung zu unterbrechen.

In zwei Fällen wurden ausgezeichnete, in fünf Fällen gute und in drei Fällen mäßige Ergebnisse erzielt. Hauptwirkungen wurden bei Adduktions- und Flexionsspastizität der Hüftgelenke festgestellt. In diesen Fällen blieb auch die Blasenfunktion erhalten. Man vermutet, daß der Verschluß der Adamkiewicz'schen Arterie hauptsächlich untere thorakale und obere lumbale Segmente beeinflußte. Anastomose zwischen der vorderen Spinalarterie und den beiden hinteren Spinalarterien kann für ausreichende kollaterale Blutzirkulation auf Konusniveau gesorgt haben.

Es wird betont, daß die perkutane Embolisierung der Adamkiewicz'schen Arterie zu einer Milderung von schwerer Spastizität der unteren Extremitäten geführt hat, ohne Änderungen der Ausscheidefunktion der spastischen Blase zu bewirken. 


\section{REFERENCES}

Avad, E. A. (1972). Phenol block for control of hip flexor and adductor spasticity. Arch. phys. Med., 53, 554-557.

BischOF, W. (I952). Die longtudinale Myelotomie erstmalig zervikal durchgeführt. Zbl. Neurochir., 12, 205-210.

Copp, E. P. \& KeEnAN, J. (1972). Phenol nerve and motor point block in spasticity. Rheum. phys. Med., II, 287-292.

Corbett, M., Frankel, H. L. \& Michaelis, L. S. (I972-73). A double blind, cross-over trial of valium in the treatment of spasticity. Paraplegia, 10, 19-22.

FoERSTER, O. (I9II). Resection of posterior spinal nerve-roots in the treatment of gastric crises and spastic paralysis. Proc. Roy. Soc. Med., 4, 226-246.

Gingras, G. (I948). Preliminary report on intrathecal alcohol injections in cases of Paraplegia. Treat. Serv. Bull. Vet. Canada, 3, 56-68.

GuttmanN, L. (I973). Spinal cord injuries: Comprehensive Management and Research, pp. 515-529. Oxford, Blackwell.

Lazorthes, G., Gouaze, A., Zadeh, J. O., Santini, J. J., Lazorthes, Y. \& Burdin, P. (I97I). Arterial vascularization of the spinal cord: Recent studies of the anastomotic substitution pathways. F. Neurosurg., 35, 253-262.

MacCarthy, C. S. \& KIEFER, J. (I954). The treatment of spastic paraplegia by selective spinal cordectomy. F. Neurosurg., I I, 539-545.

Michaelis, L. S. (1964). Myotomy of iliopsoas and obliquus externus abdominis for severe spastic flexion contracture at the hip. Paraplegia, 2, 287-294.

MunRo, D. (I945). The rehabilitation of patients totally paralyzed below the waist. Anterior rhizotomy for spastic paraplegia. New Eng. F. Med., 233, 453-46I.

PAESLACK, V. (1965-66). Drug treatment for spasticity in paraplegics. Paraplegia, 3, 9I.

SELIG, R. C. (I9I4). Arch. clin. Chir. I03, 994. quoted from Michaelis, L. S. (I976). Spasticity in spinal cord injuries. Injuries of the spine and spinal cord. Part 2. Handbook of clinical neurology, pp. 477-487. North-Holland Pub. Comp., Amsterdam. 